\title{
PENGARUH MUTU PELAYANAN PERPUSTAKAAN TERHADAP KECEPATAN MEMPEROLEH INFORMASI BAHAN PUSTAKA BAGI MAHASISWA PRODI MPI ANGKATAN 2018 DI IAIN MADURA
}

\author{
Tukad Adi Wijaya dan Mohammad Thoha \\ Prodi Manajemen Pendidikan Islam IAIN Madura \\ Email: tukad.adiwijaya@gmail.com dan thohasumberjati@gmail.com
}

\begin{abstract}
Abstrak
Pelayanan merupakan kegiatan yang pelaksanaannya dilakukan dengan mengadakan hubungan, baik secara langsung maupun tidak langsung. Pelayanan yang dimaksud disini adalah bagaimana proses pelayanan yang diterapkan dan dilakukan di perpustakaan IAIN Madura untuk mempermudah pencarian informasi bahan pustaka bagi mahasiswa, khususnya mahasiswa prodi MPI angkatan 2018. Hal ini terbukti dari hasil analisis statistik yang menunjikkan bahwa $r$ kerja 0,622 dikonsultasikan dengan nilai kritik product moment pada nilai $N=32$ dengan nilai " $r$ " kerja lebih besar dari " $r$ " tabel product moment baik pada interval $95 \%$ maupun pada interval $99 \%$ di mana menunjukkan nilai sebesar 0,349. Dengan demikian maka dapat dikatakan ada korelasi positif antara dua variabelpenelitian tersebut. seberapa besar signifikan hubungan mutu pelayanan perpustakaan terhadap kecepatan memperoleh informasi bahan pustaka bagi prodi MPI angkatan 2018 di IAIN Madura tersebut $r$ kerja dikonsultasikan dengan tabel interpretasi korelasi product moment, di mana $r$ kerja berada pada rentangan nilai antara 0,600 sampai 0,800 yang berarti korelasi atau urgensi kedua variabel berada pada taraf signifikansi yang cukup.
\end{abstract}

Kata Kunci: Mutu Pelayanan, Bahan Pustaka

\begin{abstract}
Service is an activity whose implementation is carried out by holding relationships, both directly and indirectly. The service referred to here is how the service process is implemented and carried out in the library of IAIN Madura to facilitate information retrieval of library materials for students, especiazly MPI study program students in class 2018. This is evident from the results of statistical analysis showing that the work $r 0.622$ is consulted with product criticism moment at the value of $N=32$ with the value $" r$ " of work is greater than the " $r$ " table of product moment both at $95 \%$ intervals and at 99\% intervals where it shows a value of 0.349. Thus it can be said that there is a positive correlation between the two research variables. how big is the relationship between the quality of library services to the speed of obtaining library material information for MPI study program batch 2018 in Madura IAIN $r$ work is consulted with a product moment correlation interpretation table, where $r$ work is in the range of values between 0.600 to 0.800 which means the second correlation or urgency the variable is at a sufficient level of significance.
\end{abstract}

Keyword: Service Quality, Library Materials 


\section{PENDAHULUAN}

Pelayanan merupakan salah satu unsur pendukung manajemen dalam suatu organisasi. Dalam meningkatkan mutu layanan bisa menerapkan prisip-prinsip atau acuan-acuan yang dikemukakan oleh para tokoh. Layanan merupakan ujung tombak bagaimana kita bisa digunakan kita bisa memberikan jasa kita dan bisa digunakan sebagai tolak ukur dalam menilai sejauh mana pelayanan kita bisa tertuju atau fokus ke pelanggan yang nantinya akan membawa banyak dampak bagi perkembangan perpustakaan terutama dalam penerapan layanan. Bagi dunia kepustakawanan, perkembangan teknologi informasi tersebut menjadi suatu peluang untuk membangun suatu sistem temu kembali informasi online, yaitu sistem yang mempertemukan antar kebutuhan pencarian informasi dengan sumber-sumber informasi secara online. ${ }^{1}$

Dalam pelayanan perpustakaan sekolah ada beberapa bentuk layanan yang diselenggarakan, di antaranya pelayanan bimbingan pemakai perpustakaan, pelayanan bimbingan minat baca para siswa, pelayanan peminjaman dan pengembalian bahan pustaka, dan pelayanan referensi. ${ }^{2}$ Perpustakaan merupakaan suatu lembaga yang mengurusi hal-hal yang berkaitan dengan informasi dari sejak menghimpun, mengolah, sampai menginformasikan kepada para penggunanya. ${ }^{3}$

Layanan yang diberikan kepada pengguna mencakup cara menelusur informasi berupa koleksi, fasilitas dan memanfaatkan sumber daya perpustakaan. Layanan Perpustakaan adalah suatu upaya yang dilakukan oleh pustakawan/pengelola perpustakaan agar bahan pustaka dapat dimanfaatkan dan didayagunakan dengan optimal oleh para pemakai perpustakaan, sehingga perpustakaan dapat menjalankan seluruh fungsi-fungsinya dengan baik. ${ }^{4}$

Pada dasarnya sistem informasi adalah kumpulan elemen yang saling terkait satu sama lain yang membentuk satu kesatuan untuk menginterasikan data, memperoses dan menyimpan serta mendistribusikan informasi. Data adalah kumpulan kejadian yang diangkat dari suatu kejadian. Data dapat berupa angka, huruf, simbol atau gabungan dari keduanya. Pengolahan data adalah bentuk yang berguna dan berarti berupa suatu informasi. Informasi adalah hasil dari kegiatan pengolahan data yang memberikan bentuk yang lebih berarti dari suatu kejadian. Jadi pengolahan elektronik adalah manipulasi dari data ke dalam bentuk yang lebih berati yang berupa suatu informasi dengan menggunakan suatu informasi yang menggunakan suatu alat elektronik yaitu komputer. $^{5}$

Layanan perpustakaan secara singkat dikatakan sebagai layanan "prima”, yaitu cepat, tepat, mudah, sederhana, dan murah, serta memuaskan pemakainya. Pada prinsipnya layanan perpustakaan adalah layanan jasa, oleh karena itu yang penting

1 Andi Ibrahim, "Konsep Dasar Manajemen Perpustakaan Dalam Mewujudkan Mutu layanan Prima Dengan Sistem Temu Kembali Informasi Berbasis Digital," Jurnal Ilmu Perpustakaan \& Kearsipan Khizanah Al-Hikmah 2, no. 2 (2014): 129-38.

2 Yaya Suhendar, Cara Mengelola Perpustakaan Sekolah Dasar (Jakarta: Prenada Media, 2014), 18384.

3 Fatimah Zuhra, "Pentingnya Teknologi Informasi Dalam Meningkatkan Pelayanan di Perpustakaan," Jurnal Iqra' 5, no. 1 (2011): 40.

4 Rita Purnama Sari, "Peran Pengelola Perpustakaan dalam Memberikan Pelayanan Bimbingan Pemakai di Universitas Ida Banjumi Wahab Palembang," Jurnal Intelektualita 5, no. 2 (2016): 154.

5 Hartono, Manajemen Sistem Informasi Perpustakaan (Yogyakarta: Gava Media, 2017), 21-22. 
untuk disadari oleh pengelola perpustakaan adalah bagaimana menciptakan kepercayaan, kepuasan, ketepatan, dan kecepatan. ${ }^{6}$

Berdasarkan uraian latar belakang di atas, maka peneliti merumuskan masalahmasalah yang menjadi objek kajian pada penelitian ini agar terarah dan sesuai dengan apa yang telah direncanakan. Adapun fokus masalah tersebut adalah: pertama, Adakah pengaruh mutu pelayanan perpustakaan terhadap kecepatan memperoleh informasi bahan pustaka bagi mahasiswa prodi MPI angakatan 2018 di IAIN Madura; kedua, Seberapa signifikan pengaruh mutu pelayanan perpustakaan terhadap kecepatan memperoleh informasi bahan pustaka bagi mahasiswa prodi MPI angkatan 2018 di IAIN Madura.

Kegiatan pelayanan perpustakaan merupakan inti (core) dari seluruh kegiatan perpustakaan. Keberhasilan sebuah lembaga perpustakaan sangat ditentukan oleh kualitas pelayanan perpustakaan. Layanan merupakan suatu kegiatan penyediaan bahan pustaka secara tepat, akurat, dan cepat dalam memenuhi kebutuhan informasi bagi pemakai. Tujuan perpustakaan memberikan layanan kepada masyarakat agar bahan pustaka yang telah dihimpun dan diolah sebaik-baiknya dapat dimanfaatkan oleh pembaca.

Layanan perpustakaan akan menjadi sangat penting bila perpustakaan mampu menyediakan informasi sesuai dengan kebutuhan pemakai dan berhasil menyediakan informasi bahan pustaka secara cepat dan tepat. Pelayanan yang berorientasi kepada kebutuhan pemakai sebagai tolak ukur keberhasilan dalam memberikan layanan perpustakaan. Oleh karena itu layanan perpustakaan berorientasi kepada kepuasan pengguna (user satisfaction) ${ }^{7}$.

Perpustakaan perguruan tinggi adalah perpustakaan yang terdapat di perguruan tinggi maupun lembaga yang berafiliasi dengan perguruan tinggi. perpustakaan jurusan, perpustakaan fakultas, perpustakaan universitas, perpustakaan institut, dan perpustakaan akademi adalah sebagai contoh dari perpustakaan perguruan tinggi. tujuan dan fungsi perpustakaan perguruan tinggi adalah memenuhi keperluan informasi dilingkungan perguruan tinggi (mahasiswa dan dosen), melaksanakan Tri Dharma Perguruan Tinggi dan menunjang penelitian. Oleh sebab itu, perpustakaan peruruan tinggi perlu dilengkapi bahan pustaka referensi pada semua tingkat akadenis dan disediakan ruang diskusi serta jasa peminjaman. ${ }^{8}$

Dilihat dari sifatnya, pelayanan perpustakaan bisa dikelompokkan ke dalam kategori pelayanan langsung dan pelayanan tak langsung. Yang pertama meliputi pelayanan peminjaman koleksi, pelayanan referensi, dan pelayanan bimbingan kepada pengguna/pembaca. Sedangkan yang kedua meliputi bentuk pelayanan yang mempunyai sifat tidak langsung terjadi transaksi antara petugas perpustakaan dengan penggunanya.

Jenis-jenis layanan yang diberikan kepada pengguna tidak sama disetiap perpustakaan. hal itu disesuaikan dengan keadaan dan kondisi perpustakaan, baik

6 Triana Santi, "Penerapan Teknologi Informasi Untuk Meningkatkan Kualitas Layanan Perpustakaan IAIN Sumatra Utara,” Jurnal Iqra’ 2, no. 2 (2008): 36.

7 Hartono, Dasar-dasar Manajemen Perpustakaan dari Masa-kemasa (Malang: UIN Maliki Press, 2015), $161-62$

8 Hartono, Manajemen Perpustakaan Sekolah Menuju Perpustakaan Modern dan Profesional (Yogyakarta: Ar Ruzz Media, 2016), 183. 
petugas (jumlah dan kecakapan petugas), pengguna (jumlah pengunjung dan tingkat keperluan pengguna), besar kecilnya koleksi dan jenis perpustakaan. ${ }^{9}$

Informasi adalah data yang dipeloreh ke dalam sutu bentuk yang mempu yai arti bagi si penerima dan mempunyai nilai nyata dan terasa bagi keputusan saat itu dan keputusan mendatang. Informasi adalah sebuah istilah yang tidak tepat pemakainya secara umum. Informasi dapat berisi data mentah, data tersusun, kapasitas sebuah saluran komonikasi dan sebagainya.

Dilain pihak, informasi dikatakan sebagai sekumpulan data yang dikomonikasikan dalam bentuk yang dapat dipahami. Informasi merupakan konten dari berbagai format, misalnya informasi yang tertulis atau tercetak, tersimpan dalam database, atau terkumpul dalam suatu internet. Informasi juga dapat berupa pengetahuan staf dalam suatu organisasi (perekayasan informasi, manajemen informasi, dan ilmu informasi). Istilah informasi mecakup berbagai aktifitas yang saling berkaitan menggunakan istilah kepustakawanan.

Pada dasarnya sistem informasi adalah kumpulan elemen yang saling terkait satu sama lain yan membentuk satu kesatuan untuk mengintegrasikan data, memproses dan menyimpan serta mendistribusikan informasi. Data adalah kumpulan kejadian yang diangkat dari suatu kejadian. Data dapat berupa angka, huruf, simbol atau gabungan dari keduanya. Pengolahan data adalah bentuk yang berguna dan berarti berupa suatu informasi. Informasi adalah hasil dari kegiatan pengolahan data yang memberikan bentuk dan lebih berarti dari suatu kejadian. Jadi pengolahan data elektronik adalah manipulasi dari data ke dalam bentuk yang lebih berarti yang berupa suatu informasi dengan menggunakan suatu informasi yang menggunakan suatu alat elektronik yaitu komputer.

Dalam sebuah kajian yang dilakukan di Perpustakaan IAIN Purwokerto, disebutkan bahwa manajemen dalam menciptakan layanan prima perpustakaan, dapat dilakukan melalui penerapan sistem informasi manajemen. Penerapan tersebut dengan melaksanakan fungsi manajemen mulai dari perencanaan, pelaksanaan, pengendalian, dan pengawasan telah terbukti dapat memberikan layanan prima di Perpustakaan IAIN Purwokerto. ${ }^{10}$

Dalam konsep organisasi informasi peran dan fungsi perpustakaan adalah menyediakan dan menyampaikan informasi yang dimilikinya kepada para pemakai yang membutuhkan. Untuk dapat memenuhi fungsi tersebut, informasi harus dapat dicari dan ditemukan kembali. Proses ini dalam bidang perpustakaan dikenal dengan istilah temu kembali informasi (information retrieval. Sarana yang biasa disedian oleh perpustakaan untuk menemukan informasi tersebut dinamakan sarana bibliografi, misalnya katalog, bibliografi, indeks dan lain-lain.

Bagaimanapun besarnya koleksi yang dimilki oleh sebuah perpustakaan tidak akan ada artinya jika koleksi/informasi yang relevan tidak diketahui letaknya bila diperlukan. Oleh karena itu perpustakaan perlu membangun sarana bibliografi seperti katalog sebagai sarana temu kembali informasi yang disimpannya. Apabila siatu

9 Rahayuningsih, Pengelolaan Perpustakaan (Yogyakarta: Graha Ilmu, 2007), 87-93.

10 Diyasika Ulinafiah, and Novan Ardy Wiyani. "Penciptaan Layanan Prima Melalui Penerapan Sistem Informasi Manajemen Di Perpustakaan IAIN Purwokerto." re-JIEM (Research Journal of Islamic Education Management) 2, no. 2 (2019): 223-239. 
koleksi yang relevan dengan suatu permintaan dapat diketahui keberadaannya diperpustakaa, maka hal itu berarti kecocokan yang ditemukan oleh petugas perpustakaan/pustakawanan. Dengan kata lain informasi yang terdapat pada koleksi dalam batas-batas tertentu cocok dengan informasi yang dikehendaki oleh pemakai. ${ }^{11}$

Sumber informasi merupakan sarana bibliografi sebagai bentuk jasa produk perpustakaan yang dapat diakses dan dimafaatkan oleh perpustakaan. Koleksi sumber informasi menyangkut orang/pakar, organisasi; literatur dan koleksi perpustakaan yang terbuat dalam karya cetak, karya rekam, karya tulis, artefak dan realita serta koleksi digital baik yang dapat diakses secara manual ofline maupun online. ${ }^{12}$

Bahan perpustakaan merupakan kesatuan unit informasi dalam bentuk tercetak dan rekaman dalam kontek pengembangan koleksi perpustakaan, koleksi perpustakaan adalah sebuah bahan pustaka yang dikumpulkan, diolah dan disimpan untuk disajikan kepada masyarakat pengguna dalam rangka memenuhi informasi yang dibutuhkan. Koleksi perpustakan selain mempunyai fungsi sumber informasi juga sebagai prasarana pendidikan, penelitian dan pengembang serta hiburan.

Koleksi perpustakaan pada masa kini tidak hanya berupa bahan tercetak, tetapi termasuk semua media yang memuat nilai pengetahuan dan informasi yang dikoleksi perpustakaan sesuai dengan tugas pokok dan fungsi perpustakaan tersebut. Media yang maksud antara lain adalah materi informasi terekam seperti film, CD/VCD, CD-ROM, dan media lain yang dapat diakses melalui media terpasang (online). ${ }^{13}$

Berkaitan dengan fungsi pelestarian informasi dan simber-sumber informasi ini, negara telah mengeluarkan Undang-undang No. 4/1990 tentang Serah Simpan Karya Cetak dan Karya Rekam yang berlaku efektif sejak bulan Agustus 1990. Isinya antara lain bahwa semua penerbit dan pengusaha rekaman berkewajiban untuk menyerahkan karya cetak dan karya rekamnya keperpustakaan nasional, dengan perincian sebanyak 2 (dua) buah cetakan dari setiap judul karya cetak yang dihasilkan kepada perpustakaan nasional yang berada di provinsi (sekarang namanya Perpustakaan Daerah Provinsi) yang bersangkutan, paling lambat tiga bulan sejak diterbitkan. Seangkan bagi para pengusaha rekaman yang berada di wilayah RI wajib menyerahkan 1 (satu) rekaman dari setiap judul karya rekam yang dihasilkan kepada perpustakaan nasional, dan 1 (satu) kepada perpustakaan nasional provinsi. ${ }^{14}$

Pada mulanya, yang dimaksud dengan pelayanan perpustakaan adalah menawarkan segala bahan pustaka yang dimiliki perpustakaan kepada para pengguna yang datang ke perpustakaan dan memintanya. Namun, sekarang tidak lagi seperti itu, segala bahan bacaan dan sumber-sumber informasi lainnya harus sudah tersedia di tempat di mana informasi tersebut dibutuhkan. Artinya, setiap pengguna yang membutuhkan informasi dan sumber-sumber informasi bisa mendapatkan dengan tepat dan cepat. Sumber-sumber informasi harus tersedia di tempat-tempat yang sangat memerlukannya, seperti lembaga-lembaga pendidikan, penelitian dan pusat-pusat informasi.

Perpustakaan harus melengkapi kebijakannya, prosedur pengelolaannnya, pelayanannya, koleksinya, gedungnya, dan organisasinya secara bervariasi atau

11 Hartono, Manajemen Sistem Informasi Perpustakaan, 23-24.

12 Hartono, 3-5.

13 Hartono, 38.

14 Pawit Yusuf, Ilmu Informasi Komonikasi dan Kepustakaan (Jakarta: PT. Bumi Aksara, 2016), 104. 
berbagai cara yang bisa menguntungkan bagi perpustakaan agar bisa berfungsi dengan semestinya. Perpustakaan harus memperluas aksebilitas informasi dan sumber-sumber informasi kepada masyarakat, serta menciptakan suatu lingkungan yang kondusif guna memaksimalkan potensi pemanfaatan sumber daya yang dimiliki. ${ }^{15}$

Karena secara umum perpustakaan perguruan tinggi bertugas mengelola sumbersumber informasi yang mampu mendukung pelaksanaan kurikulum perguruan tinggi yang bersangkutan, dan semua sumber informasi dimaksud bisa dimanfaatkan secara bersama perpustakaan perguruan tinggi sebagai pusat sumber belajar bersama. Semua informasi dan sumber-sumber informasi yang disediakannya secara relatif sanggup memenuhi segala kebutuhan belajar warga perguruan tinggi yang bersangkutan. Dan tentu saja informasi dan sumber-sumber informasi yang dikelolanya adalah yang berciri akademik ilmiah. ${ }^{16}$

Untuk mengetahui bagaimana dan di mana sumber-sumber informasi tersebut yang kenyataannya bersebaran dan beragam itu disimpan, serta sebagaimana pula cara untuk mengetahui secara cepat dan tepat suatu topik informasi itu disimpan, orang perlu mengenali segala jenis koleksi perpustakaan secara menyeluruh. Jenis dan sumbersumber informasi yang berada di perpustakaan, walau hanya secara umum, perlu juga diketahui. Sebabnya ialah setiap bentuk dan jenis koleksi yang disediakan perpustakaan menyimpan ragam informasi khusus yang berbeda antara jenis koleksi yang satu dengan jenis koleksi lainnya. ${ }^{17}$

\section{METODE PENELITIAN}

Penelitian ini menggunakan pendekatan kuantitatif yang menggunakan analisis data statistik. Sedangkan sifatnya adalah korelasi (reseach correlation), yaitu mencari hubungan antara variabel yang satu dengan variabel yang lain. Karena penelitian ini termasuk dalam kategori kuantitatif korelasi, maka variabel yang dilibatkan ada dua macam yaitu variabel X (independent variabel) dan variabel Y (dependent variabel).

Populasi adalah keseluruhan subjek penelitian. ${ }^{18}$ Populasi adalah wilayah generalisasi yang terjadi atas: objek/subjek yang mempunyai kualitas dan karakteristik tertentu yang ditetapkan oleh peneliti untuk dipelajari dan kemudian ditarik kesimpulannya. ${ }^{19}$ Populasi tidak berupa manusia melainkan benda-benda yang lain, popolasi juga tidak meliputi jumlah objek yang diteliti tetapi juga merupakan karakteristik atau sifat yang dimiliki oleh objek yang diteliti. Populasi dalam penelitian ini adalah 20\% dari jumlah Mahasiswa prodi MPI angkatan 2018 yang aktif di IAIN Madura, selanjutnya jika subjeknya besar dapat diambil $10-15 \%$ atau $20-25 \%$ atau lebih..

Instrumen penelitian adalah alat bantu yang digunakan oleh peneliti dalam kegiatannya mengumpulkan data guna untuk mempermudah serta hasilnya lebih baik

5 Yusuf, 207.

16 Yusuf, 173-76.

17 Yusuf, 221-22.

18 Suharsimi Arikunto, Prosedur Penelitian; Suatu Pendekatan Praktik (Jakarta: PT. Rineka Cipta, 2006), 130.

19 Sugiono, Metode Penelitian Pendidikan Pendekatan Kuantitatif, Kualitaitif, dan R dan D (Bandung: Alfabeta, 2009), 118. 
dalam artian lengkap dan sistematis, sehingga mudah diolah. ${ }^{20}$ Berikut jenis-jenis yang digunakan dalam instrumen penelitian adalah Angket atau Kuesioner

Angket atau kuesioner adalah teknik pengumpulan data dengan cara mengajukan sejumlah pertanyaan tertulis yang digunakan untuk memperoleh informasi dari responden berupa laporan tentang pribadinya, atau hal-hal yang diketahui. ${ }^{21}$

Analisis data adalah proses penyederhanaan data ke dalam bentuk yang lebih mudah dibaca dan diinterprestasi. ${ }^{22}$ Analisis yang digunakan oleh peneliti dalam penelitian ini adalah analisis data statistik korelasi dengan menggunakan rumus product moment, karena data yang diperoleh berbentuk angka-angka.

\section{HASIL DAN PEMBAHASAN}

Untuk pelayanan informasi bahan pustaka telah dilaksanakan disetiap aktif kuliyah pada setiap harinya dan bisa dikatakan sudah optimal dalam pelayanan bagi pengguna perpustakaan, khususnya dalam pelayanan pencarian informasi. Karena dalam fasilitas perpustakaan seperti komputer pencarian informasi sudah ada dan dapat digunakan bagi pengguna perpustakaan untuk mempermudah pengguna dalam mencari koleksi bahan pustaka yang dibutuhkan. Tidak hanya itu saja, dalam pelayanan pencarian informasi bagi pengguna yang diterapkan di perpustakaan, perpustakaan sudah menyediakan pelayanan langsung bagi penguna perpustakaan, yang berupa pelayanan bimbingan dan arahan bagi pengguna perpustakaan yang masih bingung dalam tata cara peminjaman koleksi buku yang ada di perpustakaan, hal ini bisa secara langsung menanyakan kepada petugas perpustakaan.

Dalam pengembangan pelayanan informasi sudah diterapkan, dan ditingkatkan seperti penambahan komputer pencarian informasi untuk mempermudah pengguna dalam pencarian bahan pustaka yang diinginkan. Dalam hal bimbingan bagi pengguna perpustakaan, perpustakaan juga telah memberikan pendidikan pemustaka atau pengenalan akademik kemahasiswaan, yang berupa bimbingan dan arahan kepada seluruh mahasiswa baru disetiap tahunnya. ${ }^{23}$

Sebagaimana yang telah diungkapkan oleh bapak Hairul A. Cahyono selaku pengembangan dan pengelolaan di perpustakaan IAIN Madura, pelayanan perpustakaan sudah optimal dan sudah terorganisir, karena dalam penugasan dimasing-masing pengelola perpustakaan IAIN Madura sudah terdaftar dan terjadwal, terutama dalam pelayanan bagi pengguna perpustakaan. Selain itu perpustakaan sudah memberikan pengenalan bagi mahasiswa baru disetiap tahunnya, yang mana dalam pengenalan ini bertujuan agar mahasiswa baru akan mengetahui tata cara dalam berkunjung maupun proses peminjaman dan pengembalian yang diterapkan diperpustakaan. ${ }^{24}$

20 Sugiono, 192.

21 Sugiono, 194.

22 Tim Penyusun Karya Tulis Ilmiah IAIN Madura, Pedoman Penulisan Karya Tulis Ilmiah (Pamekasan: iainmadura press, 2015), 19.

23 Wawancara dengan Abdus Syakur, Kepala Perpustakaan IAIN Madura ( Senin 12 November 2018) Jam 08.00.

24 Wawancara dengan Hairul A. Cahyono, Pengembangan \& Pemeliharaan Perpustakaan IAIN Madura (Selasa 13 November 2018) Jam 08.00. 
Dalam wawancara yang dilakukan kepada mahasiswa MPI angkatan 2018 dalam pelayanan yang diterapkan di perpustakaan IAIN Madura sudah cukup baik, karena dalam proses peminjaman, pengembalian, serta pencarian informasi bahan pustaka sudah lebih mudah dan cepat diakses melalui komputer pencarian. dalam kinerja petugas perpustakaan sudah cukup baik dikarenakan sudah ada petugasnya masingmasing, sepertihanya petugas penitipan barang, petugas penjaga pintu masuk yang menggunakan kartu identitas sudah baik. Dan dalam pendidikan atau pengenalan bagi mahasiswa baru memang sudah dilaksanakan disetiap tahunnya, dan itu sangat membantu kami untuk mengenal dan mengetahui dari proses berkunjung keperpustakaan, pencarian informasi-informasi yang dibutuhkan, peminjaman, hingga proses pengembalian sehingga kami lebih leluasa dan mudah dalam mengunjungi perpustakaan.

Dalam penelitian ini, penulis menyebarkan angket 32 eksamplar yang diajukan kepada Mahasiswa Prodi MPI Angkatan 2018 di IAIN Madura.

Sedangkan cara pemberian skor dari masing-masing item (soal) penulis menggunakan skala 1-3 dengan penjelasan sebagai berikut: Jawaban (a) mendapat skor 3, Jawaban (b) mendapat skor 2, Jawaban (c) mendapat skor 1. Adapun hasil penyebaran angket tersebut dapat dilihat dalam tabel 2 sampai 5.

Tabel 2. Hasil Angket Variabel X (Mutu Pelayanan Perpustakaan)

\begin{tabular}{|c|c|c|c|c|c|c|c|c|c|c|c|c|c|}
\hline \multirow{2}{*}{$\begin{array}{l}\text { No. } \\
\text { Resp }\end{array}$} & \multicolumn{10}{|c|}{ Nomor Item } & \multicolumn{3}{|c|}{ Jumlah } \\
\hline & 1 & 2 & 3 & 4 & 5 & 6 & 7 & 8 & 9 & 10 & $\mathbf{A}$ & B & $\mathbf{C}$ \\
\hline 1 & $\mathrm{a}$ & $\mathrm{b}$ & $\mathrm{a}$ & $\mathrm{a}$ & $\mathrm{a}$ & $\mathrm{b}$ & $\mathrm{b}$ & $\mathrm{b}$ & $\mathrm{a}$ & $\mathrm{a}$ & 6 & 4 & 0 \\
\hline 2 & $\mathrm{a}$ & $\mathrm{a}$ & $\mathrm{b}$ & $\mathrm{a}$ & $\mathrm{a}$ & $\mathrm{a}$ & $\mathrm{b}$ & $\mathrm{b}$ & c & $\mathrm{a}$ & 6 & 3 & 1 \\
\hline 3 & $\mathrm{a}$ & $\mathrm{a}$ & $\mathrm{a}$ & $\mathrm{a}$ & $\mathrm{a}$ & b & $\mathrm{a}$ & $\mathrm{b}$ & $\mathrm{a}$ & $\mathrm{a}$ & 8 & 2 & 0 \\
\hline 4 & $\mathrm{~b}$ & $\mathrm{a}$ & $\mathrm{a}$ & $\mathrm{a}$ & $\mathrm{c}$ & $\mathrm{c}$ & $\mathrm{b}$ & $\mathrm{c}$ & $\mathrm{c}$ & $\mathrm{c}$ & 1 & 4 & 5 \\
\hline 5 & $\mathrm{a}$ & $\mathrm{a}$ & $\mathrm{a}$ & $\mathrm{a}$ & $\mathrm{a}$ & $\mathrm{b}$ & $\mathrm{a}$ & $\mathrm{a}$ & $\mathrm{b}$ & $\mathrm{a}$ & 8 & 2 & 0 \\
\hline 6 & $\mathrm{a}$ & $\mathrm{b}$ & $\mathrm{a}$ & $\mathrm{a}$ & $\mathrm{a}$ & $\mathrm{b}$ & $\mathrm{a}$ & $\mathrm{a}$ & $\mathrm{a}$ & $\mathrm{a}$ & 8 & 2 & 0 \\
\hline 7 & $\mathrm{a}$ & $\mathrm{a}$ & $\mathrm{b}$ & $\mathrm{a}$ & $\mathrm{a}$ & $\mathrm{c}$ & $\mathrm{a}$ & $\mathrm{b}$ & $\mathrm{a}$ & $\mathrm{a}$ & 7 & 2 & 1 \\
\hline 8 & $\mathrm{a}$ & $\mathrm{a}$ & $\mathrm{a}$ & $\mathrm{a}$ & $\mathrm{b}$ & $\mathrm{b}$ & $\mathrm{b}$ & $\mathrm{a}$ & $\mathrm{a}$ & $\mathrm{a}$ & 7 & 3 & 0 \\
\hline 9 & $\mathrm{a}$ & $\mathrm{a}$ & $\mathrm{a}$ & $\mathrm{a}$ & $\mathrm{b}$ & $\mathrm{b}$ & $\mathrm{a}$ & $\mathrm{c}$ & $\mathrm{c}$ & $\mathrm{a}$ & 6 & 2 & 2 \\
\hline 10 & $\mathrm{a}$ & $\mathrm{c}$ & $\mathrm{b}$ & $\mathrm{a}$ & $\mathrm{c}$ & $\mathrm{c}$ & $\mathrm{c}$ & $\mathrm{c}$ & $\mathrm{c}$ & $\mathrm{c}$ & 2 & 1 & 7 \\
\hline 11 & $\mathrm{c}$ & $\mathrm{a}$ & $\mathrm{a}$ & $\mathrm{a}$ & $\mathrm{b}$ & $\mathrm{a}$ & $\mathrm{a}$ & $\mathrm{b}$ & $\mathrm{a}$ & $\mathrm{a}$ & 7 & 2 & 1 \\
\hline 12 & $\mathrm{a}$ & $\mathrm{a}$ & $a$ & $a$ & $\mathrm{~b}$ & $\mathrm{c}$ & $\mathrm{b}$ & $\mathrm{a}$ & $\mathrm{a}$ & $a$ & 7 & 2 & 1 \\
\hline 13 & $\mathrm{a}$ & $\mathrm{b}$ & $\mathrm{a}$ & $\mathrm{a}$ & $\mathrm{a}$ & $\mathrm{c}$ & $\mathrm{b}$ & $\mathrm{b}$ & $\mathrm{a}$ & $\mathrm{a}$ & 6 & 3 & 1 \\
\hline 14 & $\mathrm{a}$ & $b$ & $\mathrm{a}$ & $\mathrm{a}$ & $\mathrm{a}$ & $\mathrm{a}$ & $\mathrm{a}$ & $\mathrm{a}$ & $\mathrm{c}$ & $\mathrm{c}$ & 7 & 1 & 2 \\
\hline 15 & $\mathrm{a}$ & $\mathrm{b}$ & $\mathrm{a}$ & $\mathrm{a}$ & $\mathrm{b}$ & $\mathrm{a}$ & $\mathrm{a}$ & $\mathrm{a}$ & $\mathrm{b}$ & $\mathrm{a}$ & 7 & 3 & 0 \\
\hline 16 & $\mathrm{a}$ & $\mathrm{a}$ & $\mathrm{a}$ & $\mathrm{a}$ & $b$ & $b$ & $\mathrm{a}$ & $\mathrm{b}$ & $\mathrm{b}$ & $\mathrm{a}$ & 6 & 4 & 0 \\
\hline 17 & $\mathrm{~b}$ & $\mathrm{a}$ & $\mathrm{a}$ & $\mathrm{a}$ & $\mathrm{a}$ & $a$ & $\mathrm{~b}$ & $\mathrm{a}$ & $\mathrm{a}$ & $\mathrm{a}$ & 8 & 2 & 0 \\
\hline 18 & $\mathrm{a}$ & $\mathrm{b}$ & $\mathrm{b}$ & $\mathrm{a}$ & c & $\mathrm{c}$ & $\mathrm{a}$ & $\mathrm{b}$ & $\mathrm{b}$ & $\mathrm{a}$ & 4 & 4 & 2 \\
\hline 19 & $\mathrm{~b}$ & $\mathrm{c}$ & $\mathrm{a}$ & $a$ & $\mathrm{~b}$ & $\mathrm{~b}$ & $\mathrm{a}$ & $\mathrm{a}$ & $\mathrm{a}$ & $\mathrm{a}$ & 6 & 3 & 1 \\
\hline 20 & $\mathrm{a}$ & $\mathrm{a}$ & $\mathrm{b}$ & $\mathrm{a}$ & $\mathrm{a}$ & $\mathrm{b}$ & $\mathrm{a}$ & $\mathrm{a}$ & $\mathrm{a}$ & $\mathrm{a}$ & 8 & 2 & 0 \\
\hline 21 & $\mathrm{a}$ & $\mathrm{b}$ & $\mathrm{a}$ & $\mathrm{a}$ & $\mathrm{b}$ & $\mathrm{b}$ & $\mathrm{a}$ & $\mathrm{a}$ & $\mathrm{b}$ & $\mathrm{a}$ & 6 & 4 & 0 \\
\hline 22 & $\mathrm{~b}$ & $\mathrm{~b}$ & $\mathrm{a}$ & $\mathrm{a}$ & $\mathrm{a}$ & $\mathrm{b}$ & $\mathrm{a}$ & $\mathrm{b}$ & $\mathrm{b}$ & $\mathrm{a}$ & 5 & 5 & 0 \\
\hline 23 & $\mathrm{a}$ & $\mathrm{b}$ & $\mathrm{a}$ & $\mathrm{a}$ & $\mathrm{b}$ & $\mathrm{a}$ & $\mathrm{b}$ & $\mathrm{b}$ & $\mathrm{b}$ & $\mathrm{a}$ & 5 & 5 & 0 \\
\hline
\end{tabular}




\begin{tabular}{llllllllllllll}
\hline 24 & $\mathrm{~b}$ & $\mathrm{~b}$ & $\mathrm{a}$ & $\mathrm{a}$ & $\mathrm{a}$ & $\mathrm{a}$ & $\mathrm{a}$ & $\mathrm{a}$ & $\mathrm{c}$ & $\mathrm{a}$ & 7 & 2 & 1 \\
\hline 25 & $\mathrm{a}$ & $\mathrm{b}$ & $\mathrm{a}$ & $\mathrm{a}$ & $\mathrm{b}$ & $\mathrm{b}$ & $\mathrm{a}$ & $\mathrm{b}$ & $\mathrm{a}$ & $\mathrm{c}$ & 5 & 4 & 1 \\
\hline 26 & $\mathrm{a}$ & $\mathrm{b}$ & $\mathrm{a}$ & $\mathrm{a}$ & $\mathrm{b}$ & $\mathrm{b}$ & $\mathrm{a}$ & $\mathrm{b}$ & $\mathrm{a}$ & $\mathrm{c}$ & 5 & 4 & 1 \\
\hline 27 & $\mathrm{a}$ & $\mathrm{b}$ & $\mathrm{a}$ & $\mathrm{a}$ & $\mathrm{b}$ & $\mathrm{b}$ & $\mathrm{a}$ & $\mathrm{b}$ & $\mathrm{a}$ & $\mathrm{c}$ & 5 & 4 & 1 \\
\hline 28 & $\mathrm{a}$ & $\mathrm{b}$ & $\mathrm{a}$ & $\mathrm{a}$ & $\mathrm{b}$ & $\mathrm{b}$ & $\mathrm{a}$ & $\mathrm{b}$ & $\mathrm{a}$ & $\mathrm{c}$ & 5 & 4 & 1 \\
\hline 29 & $\mathrm{a}$ & $\mathrm{a}$ & $\mathrm{a}$ & $\mathrm{a}$ & $\mathrm{a}$ & $\mathrm{c}$ & $\mathrm{b}$ & $\mathrm{b}$ & $\mathrm{a}$ & $\mathrm{a}$ & 7 & 2 & 1 \\
\hline 30 & $\mathrm{a}$ & $\mathrm{b}$ & $\mathrm{b}$ & $\mathrm{a}$ & $\mathrm{b}$ & $\mathrm{c}$ & $\mathrm{b}$ & $\mathrm{c}$ & $\mathrm{b}$ & $\mathrm{a}$ & 3 & 5 & 2 \\
\hline 31 & $\mathrm{a}$ & $\mathrm{b}$ & $\mathrm{b}$ & $\mathrm{a}$ & $\mathrm{a}$ & $\mathrm{c}$ & $\mathrm{a}$ & $\mathrm{b}$ & $\mathrm{c}$ & $\mathrm{a}$ & 5 & 3 & 2 \\
\hline 32 & $\mathrm{a}$ & $\mathrm{b}$ & $\mathrm{a}$ & $\mathrm{a}$ & $\mathrm{a}$ & $\mathrm{c}$ & $\mathrm{a}$ & $\mathrm{b}$ & $\mathrm{a}$ & $\mathrm{a}$ & 7 & 2 & 1 \\
\hline
\end{tabular}

Sumber data: hasil angket

Tabel 3. Skor Angket Variabel X (Mutu Pelayanan Perpustakaan)

\begin{tabular}{|c|c|c|c|c|c|c|c|}
\hline \multirow{2}{*}{$\begin{array}{l}\text { No } \\
\text { Res }\end{array}$} & \multicolumn{3}{|c|}{ Hasil Angket } & \multicolumn{3}{|c|}{ Skor Angket } & \multirow{2}{*}{ Jumlah } \\
\hline & $\mathbf{A}$ & B & $\mathrm{C}$ & a $\times 3$ & b $\times 2$ & c $\times 1$ & \\
\hline 1 & 6 & 4 & 0 & 18 & 8 & 0 & 26 \\
\hline 2 & 6 & 3 & 1 & 18 & 6 & 1 & 25 \\
\hline 3 & 8 & 2 & 0 & 24 & 4 & 0 & 28 \\
\hline 4 & 1 & 4 & 5 & 3 & 8 & 5 & 16 \\
\hline 5 & 8 & 2 & 0 & 24 & 4 & 0 & 28 \\
\hline 6 & 8 & 2 & 0 & 24 & 4 & 0 & 28 \\
\hline 7 & 7 & 2 & 1 & 21 & 4 & 1 & 26 \\
\hline 8 & 7 & 3 & 0 & 21 & 6 & 0 & 27 \\
\hline 9 & 6 & 2 & 2 & 18 & 4 & 2 & 24 \\
\hline 10 & 2 & 1 & 7 & 6 & 2 & 7 & 15 \\
\hline 11 & 7 & 2 & 1 & 21 & 4 & 1 & 26 \\
\hline 12 & 7 & 2 & 1 & 21 & 4 & 1 & 26 \\
\hline 13 & 6 & 3 & 1 & 18 & 6 & 1 & 25 \\
\hline 14 & 7 & 1 & 2 & 21 & 2 & 2 & 25 \\
\hline 15 & 7 & 3 & 0 & 21 & 6 & 0 & 27 \\
\hline 16 & 6 & 4 & 0 & 18 & 8 & 0 & 26 \\
\hline 17 & 8 & 2 & 0 & 24 & 4 & 0 & 28 \\
\hline 18 & 4 & 4 & 2 & 12 & 8 & 2 & 22 \\
\hline 19 & 6 & 3 & 1 & 18 & 6 & 1 & 25 \\
\hline 20 & 8 & 2 & 0 & 24 & 4 & 0 & 28 \\
\hline 21 & 6 & 4 & 0 & 18 & 8 & 0 & 26 \\
\hline 22 & 5 & 5 & 0 & 15 & 10 & 0 & 25 \\
\hline 23 & 5 & 5 & 0 & 15 & 10 & 0 & 25 \\
\hline 24 & 7 & 2 & 1 & 21 & 4 & 1 & 26 \\
\hline 25 & 5 & 4 & 1 & 15 & 8 & 1 & 24 \\
\hline 26 & 5 & 4 & 1 & 15 & 8 & 1 & 24 \\
\hline 27 & 5 & 4 & 1 & 15 & 8 & 1 & 24 \\
\hline 28 & 5 & 4 & 1 & 15 & 8 & 1 & 24 \\
\hline 29 & 7 & 2 & 1 & 21 & 4 & 1 & 26 \\
\hline 30 & 3 & 5 & 2 & 9 & 10 & 2 & 21 \\
\hline 31 & 5 & 3 & 2 & 15 & 6 & 2 & 23 \\
\hline
\end{tabular}




\begin{tabular}{cccccccc}
\hline 32 & 7 & 2 & 1 & 21 & 4 & 1 & 26 \\
\hline \multicolumn{7}{c}{ Jumlah } \\
\hline
\end{tabular}

Tabel 4. Hasil Angket Variabel Y (Kecepatan Memperoleh Informasi Bahan Pustaka)

\begin{tabular}{|c|c|c|c|c|c|c|c|c|c|c|c|c|c|}
\hline \multirow{2}{*}{$\begin{array}{l}\text { No } \\
\text { Res }\end{array}$} & \multicolumn{10}{|c|}{ Nomor Item } & \multicolumn{3}{|c|}{ Jumlah } \\
\hline & 1 & 2 & 3 & 4 & 5 & 6 & 7 & 8 & 9 & 10 & $\mathbf{A}$ & $\mathbf{B}$ & $\mathbf{C}$ \\
\hline 1 & $a$ & $\mathrm{~b}$ & $b$ & $a$ & $\mathrm{a}$ & a & $a$ & $\mathrm{a}$ & $a$ & $\mathrm{a}$ & 8 & 2 & 0 \\
\hline 2 & $\mathrm{a}$ & $\mathrm{b}$ & $\mathrm{a}$ & $\mathrm{c}$ & $\mathrm{a}$ & $\mathrm{b}$ & $\mathrm{b}$ & $\mathrm{a}$ & $\mathrm{a}$ & $\mathrm{a}$ & 6 & 3 & 1 \\
\hline 3 & $\mathrm{a}$ & $\mathrm{a}$ & $\mathrm{c}$ & $\mathrm{a}$ & a & $\mathrm{b}$ & $\mathrm{a}$ & $\mathrm{a}$ & $\mathrm{b}$ & $\mathrm{a}$ & 7 & 2 & 1 \\
\hline 4 & $\mathrm{~b}$ & $\mathrm{~b}$ & $\mathrm{c}$ & $\mathrm{b}$ & $\mathrm{a}$ & $\mathrm{a}$ & $\mathrm{a}$ & $\mathrm{c}$ & $\mathrm{b}$ & $\mathrm{a}$ & 4 & 4 & 2 \\
\hline 5 & $\mathrm{a}$ & $\mathrm{a}$ & $\mathrm{a}$ & $\mathrm{a}$ & $\mathrm{a}$ & $\mathrm{a}$ & $\mathrm{a}$ & $\mathrm{a}$ & $\mathrm{a}$ & $\mathrm{a}$ & 10 & 0 & 0 \\
\hline 6 & $\mathrm{a}$ & $\mathrm{a}$ & $\mathrm{c}$ & $\mathrm{a}$ & $\mathrm{a}$ & $\mathrm{a}$ & $\mathrm{a}$ & $\mathrm{a}$ & $\mathrm{a}$ & $\mathrm{b}$ & 8 & 1 & 1 \\
\hline 7 & $\mathrm{~b}$ & $\mathrm{a}$ & $\mathrm{c}$ & $\mathrm{b}$ & $\mathrm{a}$ & $\mathrm{a}$ & $\mathrm{a}$ & $\mathrm{a}$ & $\mathrm{a}$ & $\mathrm{a}$ & 7 & 2 & 1 \\
\hline 8 & $\mathrm{a}$ & $\mathrm{a}$ & $\mathrm{b}$ & $\mathrm{b}$ & $\mathrm{a}$ & $\mathrm{a}$ & $\mathrm{a}$ & $\mathrm{b}$ & $\mathrm{a}$ & $\mathrm{a}$ & 7 & 3 & 0 \\
\hline 9 & $\mathrm{a}$ & $\mathrm{b}$ & $\mathrm{c}$ & $\mathrm{a}$ & $\mathrm{a}$ & $\mathrm{a}$ & $\mathrm{a}$ & $\mathrm{a}$ & $\mathrm{a}$ & $\mathrm{b}$ & 7 & 2 & 1 \\
\hline 10 & $\mathrm{a}$ & $\mathrm{a}$ & $\mathrm{c}$ & $\mathrm{c}$ & $\mathrm{a}$ & $\mathrm{a}$ & $\mathrm{a}$ & $\mathrm{b}$ & $\mathrm{c}$ & $\mathrm{c}$ & 5 & 1 & 4 \\
\hline 11 & $\mathrm{a}$ & $\mathrm{b}$ & $\mathrm{a}$ & $\mathrm{a}$ & $\mathrm{a}$ & $\mathrm{b}$ & $\mathrm{a}$ & $\mathrm{b}$ & $\mathrm{a}$ & $\mathrm{a}$ & 7 & 3 & 0 \\
\hline 12 & $\mathrm{a}$ & $\mathrm{a}$ & $\mathrm{a}$ & $\mathrm{b}$ & $\mathrm{b}$ & $\mathrm{b}$ & $\mathrm{a}$ & $\mathrm{a}$ & $\mathrm{b}$ & $\mathrm{a}$ & 6 & 4 & 0 \\
\hline 13 & $\mathrm{a}$ & $\mathrm{a}$ & $\mathrm{a}$ & $\mathrm{a}$ & $\mathrm{a}$ & $\mathrm{b}$ & $\mathrm{a}$ & $\mathrm{a}$ & $\mathrm{a}$ & $\mathrm{a}$ & 9 & 1 & 0 \\
\hline 14 & $\mathrm{a}$ & $\mathrm{a}$ & $\mathrm{a}$ & $\mathrm{a}$ & $\mathrm{a}$ & $\mathrm{a}$ & $\mathrm{a}$ & $\mathrm{b}$ & $\mathrm{b}$ & $\mathrm{a}$ & 8 & 2 & 0 \\
\hline 15 & $\mathrm{~b}$ & $\mathrm{~b}$ & $\mathrm{~b}$ & $\mathrm{a}$ & $\mathrm{a}$ & $\mathrm{b}$ & $\mathrm{b}$ & $\mathrm{a}$ & $\mathrm{b}$ & $\mathrm{a}$ & 4 & 6 & 0 \\
\hline 16 & $\mathrm{a}$ & $\mathrm{a}$ & $\mathrm{a}$ & $\mathrm{a}$ & $\mathrm{b}$ & $\mathrm{b}$ & $\mathrm{a}$ & $\mathrm{b}$ & $\mathrm{b}$ & $\mathrm{a}$ & 6 & 4 & 0 \\
\hline 17 & $\mathrm{c}$ & $\mathrm{a}$ & $\mathrm{a}$ & $\mathrm{b}$ & $\mathrm{a}$ & $\mathrm{b}$ & $\mathrm{a}$ & $\mathrm{a}$ & $\mathrm{a}$ & $\mathrm{a}$ & 7 & 2 & 1 \\
\hline 18 & $\mathrm{a}$ & $\mathrm{c}$ & $\mathrm{c}$ & $\mathrm{b}$ & $\mathrm{a}$ & $\mathrm{a}$ & $\mathrm{a}$ & $\mathrm{c}$ & $\mathrm{c}$ & $\mathrm{a}$ & 5 & 1 & 4 \\
\hline 19 & $\mathrm{a}$ & $\mathrm{c}$ & $\mathrm{c}$ & $\mathrm{b}$ & $\mathrm{b}$ & $\mathrm{b}$ & $\mathrm{b}$ & $\mathrm{b}$ & $\mathrm{b}$ & $\mathrm{b}$ & 1 & 7 & 2 \\
\hline 20 & $\mathrm{~b}$ & $\mathrm{a}$ & $\mathrm{b}$ & $\mathrm{a}$ & $\mathrm{a}$ & $\mathrm{a}$ & $\mathrm{a}$ & $\mathrm{a}$ & $\mathrm{a}$ & $\mathrm{a}$ & 8 & 2 & 0 \\
\hline 21 & $\mathrm{~b}$ & $\mathrm{a}$ & $\mathrm{a}$ & $\mathrm{b}$ & $\mathrm{a}$ & $\mathrm{b}$ & $\mathrm{b}$ & $\mathrm{a}$ & $\mathrm{a}$ & $\mathrm{a}$ & 6 & 4 & 0 \\
\hline 22 & $\mathrm{a}$ & $\mathrm{a}$ & c & $\mathrm{b}$ & $\mathrm{a}$ & $\mathrm{b}$ & $\mathrm{a}$ & $\mathrm{b}$ & $\mathrm{a}$ & $\mathrm{a}$ & 6 & 3 & 1 \\
\hline 23 & $\mathrm{a}$ & $\mathrm{b}$ & $\mathrm{a}$ & $\mathrm{b}$ & $\mathrm{a}$ & $\mathrm{b}$ & $\mathrm{a}$ & $\mathrm{a}$ & $\mathrm{b}$ & $\mathrm{a}$ & 6 & 4 & 0 \\
\hline 24 & $\mathrm{a}$ & $\mathrm{a}$ & $\mathrm{c}$ & $\mathrm{b}$ & $\mathrm{a}$ & $b$ & $\mathrm{a}$ & $\mathrm{a}$ & $\mathrm{a}$ & $\mathrm{a}$ & 7 & 2 & 1 \\
\hline 25 & $\mathrm{~b}$ & $\mathrm{~b}$ & $\mathrm{~b}$ & $\mathrm{a}$ & $\mathrm{a}$ & $\mathrm{a}$ & $\mathrm{a}$ & $\mathrm{b}$ & $\mathrm{a}$ & $\mathrm{b}$ & 5 & 5 & 0 \\
\hline 26 & $\mathrm{~b}$ & $\mathrm{~b}$ & $\mathrm{~b}$ & $\mathrm{a}$ & $\mathrm{a}$ & $\mathrm{a}$ & $\mathrm{a}$ & $\mathrm{b}$ & $\mathrm{a}$ & $\mathrm{b}$ & 5 & 5 & 0 \\
\hline 27 & $\mathrm{~b}$ & $\mathrm{~b}$ & $\mathrm{~b}$ & $\mathrm{a}$ & $\mathrm{a}$ & $\mathrm{a}$ & $\mathrm{a}$ & $\mathrm{b}$ & $\mathrm{a}$ & $\mathrm{b}$ & 5 & 5 & 0 \\
\hline 28 & $\mathrm{~b}$ & $\mathrm{~b}$ & $\mathrm{~b}$ & $\mathrm{a}$ & $\mathrm{a}$ & $\mathrm{a}$ & $\mathrm{a}$ & $\mathrm{b}$ & $\mathrm{a}$ & $\mathrm{b}$ & 5 & 5 & 0 \\
\hline 29 & $\mathrm{a}$ & $\mathrm{a}$ & $\mathrm{a}$ & $\mathrm{a}$ & $\mathrm{a}$ & $\mathrm{a}$ & $\mathrm{a}$ & $\mathrm{a}$ & $\mathrm{a}$ & $\mathrm{a}$ & 10 & 0 & 0 \\
\hline 30 & $\mathrm{~b}$ & $\mathrm{c}$ & $\mathrm{c}$ & $\mathrm{c}$ & $\mathrm{b}$ & $\mathrm{b}$ & c & $\mathrm{c}$ & $\mathrm{b}$ & $\mathrm{c}$ & 0 & 4 & 6 \\
\hline 31 & $\mathrm{~b}$ & $\mathrm{~b}$ & $\mathrm{c}$ & $\mathrm{b}$ & $\mathrm{a}$ & $\mathrm{a}$ & $\mathrm{a}$ & $\mathrm{b}$ & $\mathrm{a}$ & $\mathrm{b}$ & 4 & 5 & 1 \\
\hline 32 & $\mathrm{a}$ & $\mathrm{b}$ & $\mathrm{a}$ & $\mathrm{a}$ & $\mathrm{a}$ & $\mathrm{a}$ & $\mathrm{a}$ & $\mathrm{b}$ & $\mathrm{a}$ & $\mathrm{a}$ & 8 & 2 & 0 \\
\hline
\end{tabular}

Tabel 5. Skor Angket Variabel Y (Kecepatan Memperoleh Informasi Bahan Pustaka)

\begin{tabular}{cccccccc}
\hline No & \multicolumn{3}{c}{ Hasil Angket } & \multicolumn{3}{c}{ Skor Angket } & \multirow{2}{*}{ Jumlah } \\
\cline { 2 - 7 } Res & A & B & C & a x 3 & b x 2 & c x 1 & \\
\hline 1 & 8 & 2 & 0 & 24 & 4 & 0 & 28 \\
\hline
\end{tabular}




\begin{tabular}{|c|c|c|c|c|c|c|c|}
\hline 2 & 6 & 3 & 1 & 18 & 6 & 1 & 25 \\
\hline 3 & 7 & 2 & 1 & 21 & 4 & 2 & 27 \\
\hline 4 & 4 & 4 & 2 & 12 & 8 & 2 & 22 \\
\hline 5 & 10 & 0 & 0 & 30 & 0 & 0 & 30 \\
\hline 6 & 8 & 1 & 1 & 24 & 2 & 1 & 27 \\
\hline 7 & 7 & 2 & 1 & 21 & 4 & 1 & 26 \\
\hline 8 & 7 & 3 & 0 & 21 & 6 & 0 & 27 \\
\hline 9 & 7 & 2 & 1 & 21 & 4 & 1 & 26 \\
\hline 10 & 5 & 1 & 4 & 15 & 2 & 4 & 21 \\
\hline 11 & 7 & 3 & 0 & 21 & 6 & 0 & 27 \\
\hline 12 & 6 & 4 & 0 & 18 & 8 & 0 & 26 \\
\hline 13 & 9 & 1 & 0 & 27 & 2 & 0 & 29 \\
\hline 14 & 8 & 2 & 0 & 24 & 4 & 0 & 28 \\
\hline 15 & 4 & 6 & 0 & 12 & 12 & 0 & 24 \\
\hline 16 & 6 & 4 & 0 & 18 & 8 & 0 & 26 \\
\hline 17 & 7 & 2 & 1 & 21 & 4 & 1 & 26 \\
\hline 18 & 5 & 1 & 4 & 15 & 2 & 4 & 21 \\
\hline 19 & 1 & 7 & 2 & 3 & 14 & 2 & 19 \\
\hline 20 & 8 & 2 & 0 & 24 & 4 & 0 & 28 \\
\hline 21 & 6 & 4 & 0 & 18 & 8 & 0 & 26 \\
\hline 22 & 6 & 3 & 1 & 18 & 6 & 1 & 25 \\
\hline 23 & 6 & 4 & 0 & 18 & 8 & 0 & 26 \\
\hline 24 & 7 & 2 & 1 & 21 & 4 & 1 & 26 \\
\hline 25 & 5 & 5 & 0 & 15 & 10 & 0 & 25 \\
\hline 26 & 5 & 5 & 0 & 15 & 10 & 0 & 25 \\
\hline 27 & 5 & 5 & 0 & 15 & 10 & 0 & 25 \\
\hline 28 & 5 & 5 & 0 & 15 & 10 & 0 & 25 \\
\hline 29 & 10 & 0 & 0 & 30 & 0 & 0 & 30 \\
\hline 30 & 0 & 4 & 6 & 0 & 8 & 6 & 14 \\
\hline 31 & 4 & 5 & 1 & 12 & 10 & 1 & 23 \\
\hline 32 & 8 & 2 & 0 & 24 & 4 & 0 & 28 \\
\hline \multicolumn{7}{|c|}{ Jumlah } & 811 \\
\hline
\end{tabular}

Adapun langkah-langkah perhitungan dapat diuraikan sebagai berikut: (a) Membuat tabel kerja atau tabel perhitungan yang terdiri dari delapan kolom: Kolom 1: Subjek penelitian, Kolom 2: Skor variabel X, Kolom 3: Skor variabel Y, Kolom 4: Deviasi skor $\mathrm{X}$ terhadap $\mathrm{Mx}$; diperoleh dengan rumus; $\mathrm{x}=\mathrm{X}-\mathrm{Mx}$, Kolom 5: Deviasi skor $\mathrm{Y}$ terhadap My; diperoleh dengan rumus; $\mathrm{y}=\mathrm{Y}-\mathrm{My}$, Kolom 6: Hasil penguadratan seluruh deviasi skor $\mathrm{X}$ (yaitu ${ }_{\mathrm{x}}^{2}$ ), Kolom 7: Hasil penguadratan seluruh deviasi skor $\mathrm{Y}$ (yaitu ${ }^{2}$ ), Kolom 8: Hasil perkalian antara deviasi skor X (yaitu $\mathrm{x}$ ) dan deviasi skor $\mathrm{Y}$ (yaitu $\mathrm{y}$ ) $=\mathrm{xy}$. (b) Mencari angka indeks korelasi $\mathrm{r}$ product moment antara variabel $\mathrm{X}$ dan vatiabel $\mathrm{Y}\left(\mathrm{r}_{\mathrm{xy}}\right)$. (c) Memberikan interpretasi terhadap $\mathrm{r}_{\mathrm{xy}}$ serta menarik kesimpulannya, 
yang dapat dilakukan secara sederhana atau dilakukan dengan jalan berkonsultasi pada tabel nilai r product moment. ${ }^{25}$

Untuk lebih jelasnya mengenai tabel persiapan menghitung "r" kerja dapat dilihat pada tabel 6.

Tabel 6. Persiapan Menghitung "r" Kerja

\begin{tabular}{cccccccc}
\hline $\begin{array}{c}\text { No } \\
\text { Responden }\end{array}$ & $\mathbf{X}$ & $\mathbf{Y}$ & $\mathbf{X}$ & $\mathbf{y}$ & $\mathbf{x}^{\mathbf{2}}$ & $\mathbf{y}^{\mathbf{2}}$ & $\mathbf{x y}$ \\
\hline 1 & 26 & 28 & 1,16 & 2,66 & 1,3456 & 7,0756 & 3,0856 \\
\hline 2 & 25 & 25 & 0,16 & $-0,34$ & 0,0256 & 0,1156 & $-0,0544$ \\
\hline 3 & 28 & 27 & 3,16 & 1,66 & 9,9856 & 2,7556 & 5,2456 \\
\hline 4 & 16 & 22 & $-8,84$ & $-3,34$ & 78,1456 & 11,1556 & 29,5256 \\
\hline 5 & 28 & 30 & 3,16 & 4,66 & 9,9856 & 21,7156 & 14,7256 \\
\hline 6 & 28 & 27 & 3,16 & 1,66 & 9,9856 & 2,7556 & 5,2456 \\
\hline 7 & 26 & 26 & 1,16 & 0,66 & 1,3456 & 0,4356 & 0,7656 \\
\hline 8 & 27 & 27 & 2,16 & 1,66 & 4,6656 & 2,7556 & 3,5856 \\
\hline 9 & 24 & 26 & $-0,84$ & 0,66 & 0,7056 & 0,4356 & $-0,5544$ \\
\hline 10 & 15 & 21 & $-9,84$ & $-4,34$ & 96,8256 & 18,8356 & 42,7056 \\
\hline 11 & 26 & 27 & 1,16 & 1,66 & 1,3456 & 2,7556 & 1,9256 \\
\hline 12 & 26 & 26 & 1,16 & 0,66 & 1,3456 & 0,4356 & 0,7656 \\
\hline 13 & 25 & 29 & 0,16 & 3,66 & 0,0256 & 13,3956 & 0,5856 \\
\hline 14 & 25 & 28 & 0,16 & 2,66 & 0,0256 & 7,0756 & 0,4256 \\
\hline 15 & 27 & 24 & 2,16 & $-1,34$ & 4,6656 & 1,7956 & $-2,8944$ \\
\hline 16 & 26 & 26 & 1,16 & 0,66 & 1,3456 & 0,4356 & 0,7656 \\
\hline 17 & 28 & 26 & 3,16 & 0,66 & 9,9856 & 0,4356 & 2,0856 \\
\hline 18 & 22 & 21 & $-2,84$ & $-4,34$ & 8,0656 & 18,8356 & 12,3256 \\
\hline 19 & 25 & 19 & 0,16 & $-6,34$ & 0,0256 & 40,1956 & $-1,0144$ \\
\hline 20 & 28 & 28 & 3,16 & 2,66 & 9,9856 & 7,0756 & 8,4056 \\
\hline 21 & 26 & 26 & 1,16 & 0,66 & 1,3456 & 0,4356 & 0,7656 \\
\hline 22 & 25 & 25 & 0,16 & $-0,34$ & 0,0256 & 0,1156 & $-0,0544$ \\
\hline 23 & 25 & 26 & 0,16 & 0,66 & 0,0256 & 0,4356 & 0,1056 \\
\hline 24 & 26 & 26 & 1,16 & 0,66 & 1,3456 & 0,4356 & 0,7656 \\
\hline 25 & 24 & 25 & $-0,84$ & $-0,34$ & 0,7056 & 0,1156 & 0,2856 \\
\hline 26 & 24 & 25 & $-0,84$ & $-0,34$ & 0,7056 & 0,1156 & 0,2856 \\
\hline 27 & 24 & 25 & $-0,84$ & $-0,34$ & 0,7056 & 0,1156 & 0,2856 \\
\hline 28 & 24 & 25 & $-0,84$ & $-0,34$ & 0,7056 & 0,1156 & 0,2856 \\
\hline 29 & 26 & 30 & 1,16 & 4,66 & 1,3456 & 21,7156 & 5,4056 \\
\hline 30 & 21 & 14 & $-3,84$ & $-11,34$ & 14,7456 & 128,5956 & 43,5456 \\
\hline 31 & 23 & 23 & $-1,84$ & $-2,34$ & 3,3856 & 5,4756 & 4,3056 \\
\hline Jml & 26 & 28 & 1,16 & 2,66 & 1,3456 & 7,0756 & 3,0856 \\
\hline 32 & 811 & - & - & 276,22 & 325,22 & 186,72 \\
\hline 19 & 26 & & &
\end{tabular}

Berdasarkan tabel di atas, maka diperoleh keterangan :

25 Anas Sudijono, Pengantar Statistik Pendidikan (Jakarta: PT. Raja Grafindo Persada, 2003), 204-205. 


$$
\begin{aligned}
& \mathrm{N}=32, \quad \sum x=795, \quad \sum y=811, \quad M x=\frac{\sum x}{N}=\frac{795}{32}=24,84 \quad M y=\frac{\sum y}{N}=\frac{811}{32}=25,34, \\
& \sum x^{2}=276,22, \quad \sum y^{2}=325,22, \quad \sum x y=186,72, \quad \sum x^{2} \cdot \sum y^{2}=89831,79, \\
& \sqrt{\left(\sum x^{2}\right)\left(\sum y^{2}\right)}=299,72
\end{aligned}
$$

Kemudian untuk menganalisa angka-angka di atas tersebut dapat dimasukkan ke dalam rumus korelasi product moment sebagai berikut :

$$
\begin{aligned}
r x y & =\frac{\sum x y}{\sqrt{\left(\sum x^{2}\right)\left(\sum y^{2}\right)}} \\
& =\frac{186,72}{\sqrt{(276,22)(325,22)}} \\
& =\frac{186,72}{\sqrt{89831,79}} \\
& =\frac{186,72}{299,72} \\
& =0,622
\end{aligned}
$$

Berdasarkan hasil analisis data yang diperoleh dapat diketahui bahwa $\mathrm{r}$ kerja sebesar 0,622. Untuk mengetahui diterima tidaknya hipotesis yang telah diajukan penulis hipotesis kerja dan hipotesis terarah, maka nilai " $r$ " kerja tersebut dikonsultasikan dengan harga kritik " $\mathrm{r}$ " product moment.

Untuk mengetahui " $\mathrm{r}$ " kerja dapat dilihat pada harga kritik " $\mathrm{r}$ " product moment, baik dalam interval kepercayaan 95\% maupun 99\% sehingga akan diketahui hubungan kedua variabel penelitian ini.

Berdasarkan hasil analisis data yang diperoleh dapat diketahui bahwa $r$ kerja sebesar 0,210. Untuk mengetahui diterima tidaknya hipotesis yang telah diajukan penulis hipotesis kerja dan hipotesis terarah, maka nilai "r" kerja tersebut dikonsultasikan dengan harga kritik "r" product moment.

Dengan harga kritik " $r$ " product moment, hipotesis kerja (Ha) yang menyatakan bahwa "ada pengaruh mutu pelayanan perpustakaan terhadap kecepatan memperoleh informasi bahan pustaka bagi Mahasiswa Prodi MPI angkatan 2018 di IAIN Madura" diterima.

Dari hipotesis terarah yang menyatakan bahwa "cukup signifikan pengaruh mutu pelayanan perpustakaan terhadap kecepatan memperoleh informasi bahan pustaka bagi Mahasiswa Prodi MPI Angkatan 2018 di IAIN Madura" diterima.

Untuk mengetahui seberapa besar signifikan pengaruh mutu pelayanan perpustakaan terhadap kecepatan memperoleh informasi bahan pustaka bagi Mahasiswa Prodi MPI Angkatan 2018 di IAIN Madura.

Tabel 1. Tabel interpretasi nilai " $r$ " 


\begin{tabular}{ll}
\hline Antara 0,800 sampai dengan 1,00 & Tinggi \\
\hline Antara 0,600 sampai dengan 0,800 & Cukup \\
\hline Antara 0,400 sampai dengan 0,600 & Agak \\
\hline Antara 0,200 sampai dengan 0,400 & Rendah \\
\hline Antara 0,000 sampai dengan 0,200 & Sangat rendah \\
\hline
\end{tabular}

Berdasarkan tabel interpretasi nilai " $r$ " di atas dapat diketahui bahwa nilai " $r$ " kerja sebesar 0,622 berada pada rentangan angka antara 0,600 sampai 0,800 dengan interpretasi cukup.

Dengan demikian, maka hipotesis alternatif yang diajukan diterima bahwa ada pengaruh mutu pelayanan perpustakaan terhadap kecepatan memperoleh informasi bahan pustaka bagi Mahasiswa Prodi MPI Angkatan 2018 di IAIN Madura dengan kateria cukup, dan hipotesis terarah yang diajukan juga diterima.

Seberapa signifikan pengaruh mutu pelayanan perpustakaan terhadap kecepatan memperoleh informasi bahan pustaka bagi mahasiswa prodi MPI angkatan 2018 di IAIN Madura.

Pada akhirnya perpustakaan didirikan untuk memfasilitasi terciptanya masyarakat yang terdidik, terpelajar, terbiasa membaca, dan budaya tingi. Masyarakat yang demikian itu mempunyai pandangan dan wawasan yang luas, mandiri, percaya diri, dan terbuka untuk senantiasa mengikuti perkembangan dan kemajuan zaman. ${ }^{26}$

Perpustakaan sebagai pengelola dan penyedia informasi diharapkan mampu memenuhi kebutuhan penggunanya. Unrtuk secara rutin perpustakaan melaksanakan kegiatan-kegiatan pokok sebagai berikut:

Pengembangan koleksi, yang meliputi pemulihan, pemesanan, pembelian, dan inventarisasi bahan pustaka.

Pengelolaan koleksi, yang meliputi penentuan subjek, klasifikasi, penentuan tajuk, entri data, dan pemberian kelengkapan koleksi agar dapat dilayankan kepada pengguna perpustakaan.

Layanan pengguna, yang meliputi loker, layanan sirkulasi, layanan ruang baca, layanan terbitan berkala, layanan refensi, dan penelususran informasi, layanan workstation, layanan fotokopi, layanan pendidikan pengguna, dan lain-lain.

Pemeliharaan koleksi, yang meliputi pelestarian, pengawetan, dan perbaikan bahan pustaka. ${ }^{27}$

\section{KESIMPULAN DAN SARAN}

Dari hasil penelitian yang dilakukan, dapat disimpulakan bahwa ada pengaruh mutu pelayanan perpustakaan terhadap kecepatan memperoleh informasi bahan pustaka bagi Mahasiswa Prodi MPI Angakatan 2018 di IAIN Madura. Dengan nilai " $r$ " kerja sebesar 0.622 lebih besar dari "r" tabel product moment baik pada interval 95\% maupun pada interval $99 \%$ di mana pada $\mathrm{N}=32$ menunjukkan nilai sebesar 0.349 dan 0.449 .

Setelah peneliti mencocokkan dengan taraf interpretasi, maka disimpulkan bahwa dalam penelitian yang saya ajukan ini, mutu pelayan perpustakaan berpengaruh terhadapa kecepatan memperoleh informasdi bahan pustaka bagi Mahasiswa Prodi MPI

26 Rahayuningsih, Pengelolaan Perpustakaan, 2.

27 Rahayuningsih, 12. 
Angkatan 2018 di IAIN Madura. Hal ini dibuktikan dengan nilai " $r$ " kerja setelah dikonsultasikan pada tabel interpretasi produk, moment, nilai " $r$ " kerja tersebut berada pada 0.600 sampai 0.800 dengan interpretasi cukup.

Berdasarkan hasil penelitian yang telah dipaparkan di atas, maka selanjutnya peneliti menyampaikan saran-saran yang kiranya dapat bermanfaat bagi pihak-pihak yang terkait atas hasil penelitian ini. Adapun saran-saran tersebut yaitu sebagai berikut: (a) Kepada kepala Perpustakaan IAIN Madura hendaknya memperbaiki kondisi pengelolaan pelayanan yang dilakukan di Perpustakaan IAIN Madura, memperbesar usaha untuk meningkatkan profesi staf perpustakaan, terutama dalam pelayanan informasi perpustakaan dan peminjaman bahan pustaka. Sehingga Mahasiswa mudah dalam pencarian sumber-sumber informasi bahan pustaka khusunya Mahasiswa Prodi MPI Angkatan 2018. (b) Kepada mahasiswa IAIN Madura, khususnya mahasiswa prodi MPI angkatan 2018 hendaknya ikut bertanggung jawab dan memberikan dukungan baik moril maupun materil terhadap perpustakaan IAIN Madura, dan ikut serta (berpartisipasi) atas keputusan-keputusan ataupun peraturan-peraturan yang di laksanakan di perpustakaan IAIN Madura.

\section{DAFTAR PUSTAKA}

Arikunto, Suharsimi. Prosedur Penelitian; Suatu Pendekatan Praktik. Jakarta: PT. Rineka Cipta, 2006.

Bafadal, Ibrahim. Pengelolaan Perpustakaan Sekolah. Jakarta: Bumi Aksara, 2015.

Direktorat Jenderal Pembinaan Kelembagaan Agama Islam, Buku Pedoman Perpustakaan Dinas Departemen Agama R,I.. Jakarta: Biro Hukum dan Humas, 2000.

Hartono. Dasar-dasar Manajemen Perpustakaan dari Masa-kemasa. Malang: UIN Maliki Press, 2015.

—. Manajemen Perpustakaan Sekolah Menuju Perpustakaan Modern dan Profesional. Yogyakarta: Ar Ruzz Media, 2016.

- Manajemen Sistem Informasi Perpustakaan. Yogyakarta: Gava Media, 2017.

Ibrahim, Andi. "Konsep Dasar Manajemen Perpustakaan Dalam Mewujudkan Mutu layanan Prima Dengan Sistem Temu Kembali Informasi Berbasis Digital." Jurnal Ilmu Perpustakaan \& Kearsipan Khizanah Al-Hikmah 2, no. 2 (2014): 129-38.

Ishak. "Pengelolaan Perpustakaan Berbasis Teknologi Informasi." Jurnal Studi Perpustakaan dan Informasi, Vol. 4, No 2, Desember 2008.

Kadir, Abdul. Pengenalan Sistem Informasi. Yogyakarta: ANDI Yogyakarta, 2003.

Madura, Tim Penyusun Karya Tulis Ilmiah IAIN. Pedoman Penulisan Karya Tulis Ilmiah. Pamekasan: iainmadura press, 2015.

Margono S. Metodologi Penelitian Pendidikan. Jakarta: Rineka Cipta, 2001.

Nazir, Moh. Metode Penelitian. Bogor: Ghalia Indonesia, 2009.

Rahayuningsih. Pengelolaan Perpustakaan. Yogyakarta: Graha Ilmu, 2007.

Rifai, Agus. Perpustakaan Islam. Jakarta: Rajawali Pers, 2013.

Santi, Triana. "Penerapan Teknologi Informasi Untuk Meningkatkan Kualitas Layanan Perpustakaan IAIN Sumatra Utara." Jurnal Iqra' 2, no. 2 (2008).

Sari, Rita Purnama. "Peran Pengelola Perpustakaan dalam Memberikan Pelayanan Bimbingan Pemakai di Universitas Ida Banjumi Wahab Palembang." Jurnal Intelektualita 5, no. 2 (2016). 
Subana, Moersetyo Rahadi, dan Sudrajat. Statistik Pendidikan. Bandung: Pustaka Setia, 2000.

Sudijono, Anas. Pengantar Statistik Pendidikan. Jakarta: PT. Raja Grafindo Persada, 2003.

Sugiono. Metode Penelitian Pendidikan Pendekatan Kuantitatif, Kualitaitif, dan $R$ dan D. Bandung: Alfabeta, 2009.

Suhendar, Yaya. Cara Mengelola Perpustakaan Sekolah Dasar. Jakarta: Prenada Media, 2014.

Suhendar, Yaya dan Pawit Yusuf. Pedoman Penyelenggaraan Perpustakaan Sekolah, Jakarta: Prenada Media Group, 2016.

Suwarno, Wiji. Ilmu Perpustakaan \& Kode Etik Pustakawan, Yokyakarta: Ar-Ruzz Media, 2015.

Ulinafiah, Diyasika, and Novan Ardy Wiyani. "Penciptaan Layanan Prima Melalui Penerapan Sistem Informasi Manajemen Di Perpustakaan IAIN Purwokerto." reJIEM (Research Journal of Islamic Education Management) 2, no. 2 (2019): 223239.

Yusuf, Pawit. Ilmu Informasi Komonikasi dan Kepustakaan. Jakarta: PT. Bumi Aksara, 2016.

Zuhra, Fatimah. "Pentingnya Teknologi Informasi Dalam Meningkatkan Pelayanan di Perpustakaan.” Jurnal Iqra' 5, no. 1 (2011): 40. 